\title{
A NOÇÃO DE CONTRATO NA HISTÓRIA DOS PACTOS
}

\author{
JUDITH MARTINS-COSTA
}

\section{INTRODUÇÃO}

A noção de contrato nasce, no sentido moderno, com idéia de autonomia da vontade ${ }^{1}$ e é por essa via que pretendo procurar os possíveis pontos de contacto entre o conceito jurídico de contrato, ${ }^{2}$ o pacto fáustico e outros pactos.

Parece hoje incontroverso que o contratualismo, ou a explicação da ordem jurídica como resultado de um encontro de vontades tenha raízes mais antigas, já sendo visualizado na filosofia de Epicuro. ${ }^{3}$ Me refiro, no entanto de forma menos abrangente, ao instituto do contrato como vínculo eminentemente bilateral, com conteúdo patrimonial e gerador de deveres e obrigações para as partes que o firmam: é este conceito, hoje tão discutido no direito po-

Judith Martins Costa. Professora na Faculdade de Direito da Universidade Federal do Rio Grande do Sul.

1 É das mais ricas a bibliografia sobre este assunto. Ver, entre outros: André-Jean Arnaud, Les origines doctrinales du code civil français, Paris, L. G. D. J., 1969; René Sève, Leibniz et l'école moderne du droit naturel, Paris, P. U. F., 1969; Guido Alpa, Definizione codicistica di contrato e vinculum juris, in Materiali per una storia della cultura giuridica, v. 20, p. 135-54; Jean-Louis Gazzani ja 37-45; Michel Villey, Essor tecan de philosophie du 77-45, Miche Vill droit, Pars, Dallez, Hespanha), Lisboa, Ed. Fundação Calouste Gulbenkian, s. d., p. 330 e ss.; Alfred Rieg, Le rôle de la volonté dans la formation de l'acte juridique d'après les doctrines allemandes du XIXème siècle, in Archives de Philosophie du Droit, 1957, p. 125-37.

2 Muito se discute sobre a possibilidade de ser afirmada a existência de um conceito de contrato. Evidentemente, rejeitada a ficcão da neutralidade ou da aistoricidade dos conceitos - quaisquer que sejam - não se pode admitir a univocidade. Baseio-me, portanto, em certos conceitos de contrato, preenchidos historicamente, tendo presente a advertencia de Eros Roberto Grau que, na linguagem jurídica os conceitos não se referem simplesmente a coisas ou objetos - como ocorre na linguagem comum - mas se reconduzem a significações, atribuiveis a coisas, objetos, estados o situações de modo que "o conceito jurídico é signo de significações" (Ver Direito, conceitos e normas jurídicas, São Paulo, Ed. Revista dos Tribunais, 1988, p. 64)

3 Assim, Miguel Reale, Contratualismo - posição de Rousseau e de Kant, in Horizontes do direito e da história, Rio de Janeiro, Saraiva, 1977, p. 128-50. Sobre as implicações na Idade Média e Moderna, Jean-Fabien Spitz, Le contrat social, Droits, 12, 1990, p. 25-35 e G. Augé, Le contrat l'b́lution du consensulisme chez Grotius, in Archives de Philosophie du Droit, 1968 p. $99=114$. sitivo, ${ }^{4}$ tão sensivel à intervenção legislativa e ao direito judicial - onde tem sido admitida a intervenção positiva dos juízes para adequá-lo à sua função econômico-social e a um parâmetro concreto de justiça comutativa - que pretendo enfocar para tentar descobrir, através dos traços mais largos da história de um conceito, onde está o pacto, onde está o indivíduo, onde está a sociedade.

São essas as linhas de indagação subjacentes ao presente estudo que, na tentativa de respondê-las, enfocará, primeiramente, a noção tradicional de contrato, centrada na tutela da vontade individual para, após, delinear os possíveis pressupostos que estão na base da tutela da confiança para saber se, afinal, se confirma ou não a manutenção do conceito - e de qual conceito - de contrato.

Para isso parece-me necessário, contudo, recorrer ao fascinante campo da História dos conceitos. Como assinalou Ricardo Orestano, "as palavras e o uso que delas é feito possuem uma sua própria historicidade, que acaba por condicionar o próprio instrumento", 5 de modo que é essencial ter-se em conta os seus empregos e as suas implicações históricas, mormente quando se trata do contrato - um conceito, um instrumento, a matriz de uma relação que, pelo menos há dois mil anos, vem acompanhando a humanidade, com conotações que permanentemente se transformam. ${ }^{6}$

\section{I - OS FUNDAMENTOS DE UM CONCEITO DE CONTRATO}

1. No contrato, compreendido como expressão de um vínculo bilateral com conteúdo patrimonial e obrigatório aos seus figurantes, tudo escapa à redução do dogmatismo. As relações contratuais integram, segundo afirma a antropologia jurídica, a própria história das relações humanas. ${ }^{7}$ Já era, pois, tal figura, conhecida e qualificada numa cultura jurídica sofisticada como a romana.

Todavia, a noção romana de contractus pouco ou nada tem a ver com aquela fixxada nos Códigos modernos que ainda nos regem, hoje dita "em cri$\mathrm{se}^{\prime \prime}$ : no direito romano o termo, com conotação objetiva, era utilizado para designar certos tipos especiais de acordos, reconhecidos como obrigatórios e providos de actio - vale dizer, a possibilidade de recurso à autoridade estatal para fazer valer a força do acordado - discernindo-o, esse termo, de outros acordos, não obrigatórios e nomeados precisamente de pacta.

Estes, pactum ou conventum, significavam exatamente o acordo sobre determinados pontos, os quais, no entanto, em razão do extremado formalis-

4 Para uma síntese ver Denis Tallon, L'évolution des idées en matière de contrat: survol comparatif, in Droits, 1990, p. 81-91.

5 Em: Norma statuida e norma statuente - contributo alle semantiche di una metafora, in Materiali per una storia della cultura giuridica, anno Xiii, n. 2, 1983, p. 313-50.

6 Tratei desse tema, sob o ponto de vista do direito positivo brasileiro, em: Crise e modificação da nocão de contrato no direito brasileiro, in Revista Direito do Consumidor, v. 3, São Paulo, Ed. Revista dos Tribunais, 1992, p. 125-54.

7 Assim Jacques Ghestin, La notion de contrat, in Droits, 12, 1990, p. 9.

Organon $19 / 1992$ 
mo, característico do direito romano, não eram idôneos para constituir vínculo juridico obrigatório, porque carentes do revestimento das formalidades prescritas. Nesses casos, sem a força do direito que era atribuída à dicção de certas fórmulas, não haveria ação, não surgiriam efeitos de direito. Uma compra $\mathrm{e}$ venda que não importasse na formalidade da tradictio era considerada, por exemplo, pacta nuda. Daí o brocardo que continuou, inclusive na primeira Idade Média, a ser repetido pelos romanistas: "Ex nudo pacto nulla nascitur actio".

Diferentemente, o contractus - elipse de negotium contractus - era visualizado como um vínculo objetivo, mais propriamente referenciado aos efe $i$ tos ou conseqüências jurídicas do acordo. A objetividade decorria do fato de não se considerar a vontade subjetiva do agente como um fator constitutivo do vinculo, estando este dependente, como se viu, da adstrição às fórmulas préestabelecidas. Não se pensava, então, em enxertar no termo a idéia da expressão da manifestação da vontade humana, ou da autodeterminação individual.

2. Essa foi a noção que - inobstante as mitigações advindas do direito pretoriano, flexível e avesso à rigidez do formalismo - em largos traços, alcançou a Europa continental no século XIII, época em que, nas nascentes universidades foi "redescoberto" o direito romano justinianeu sendo então lançados os fundamentos do que se convencionou chamar de ciência jurídica ocidental. ${ }^{8}$

Nada mais distante, portanto, da concepção voluntarista acolhida no primeiro código moderno - o Código Civil Francês, de 1804, conhecido como Code Napoléon - onde o contrato é visto como a suprema metáfora da liberdade individual do cidadão e, por isto mesmo, é considerado intrinsecamente justo: "qui dit contractuel dit juste", rezava um axioma, com a força de indiscutivel verdade, colocando-se aí, em primeiro plano, o aspecto subjetivo do vínculo. A justiça, intrinseca, decorreria tanto da liberdade quanto da igualdade dos contratantes frente à ordem político-jurídica: uma era correlata à outra.

3. Para se chegar até aí foram necessários pelo menos cinco séculos de ingente esforço da filosofia, esforço cujas raízes estão fincadas na escolástica tardia

8 Para o estudo do contrato no direito medieval ver, por todos, o monumental estudo de Franos cosco Ca

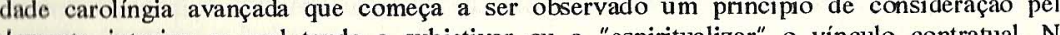

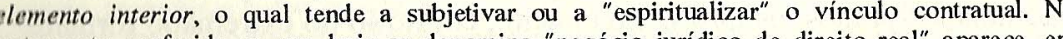
tratamento conferido ao que hoje se denomina "negócio jurldico de direito real" aparece, em matéria de defesa, a boa fé no sentido subjetivo, isto é, "consciência interna de não estar lesionando direito de outrem". O primeiro documento que dá conta dessa vertente diz respeito uma lide entre o proprietário de um terreno que diz a um terceiro que esse invadiu a sua terra; pretenso invasor se defende afirmando que a propriedade é sua e mostra, como prova, o contrato de compra e venda que havia firmado. $\mathrm{O}$ que se diz proprietário afirma, em contrário, que tal contrato nûo pode atingir o seu direito de propriedade, porquanto o que havia vendido ao litigante Con

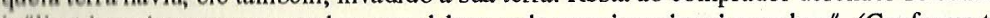
Caplitulare Italicum, narrado por Calasso, op. cit. p. 120 e 121.) através das obras de Guilherme de Ockhan e de Duns Scotus, expoentes do nominalismo. ${ }^{9}$

Nesse preciso momento - o século XIV - o voluntarismo que se encontru na gênese do conceito de contrato por nós recebido inicia a sua trajetória, quo será secular e dominará todo o raciocínio político e jurídico do mundo ocidental.

Isto porque a premissa onde se funda o direito moderno dos contratos $\mathrm{e}$ de sua disciplina jurídica provém da releitura procedida por de Ockhan e Scotus ao direito natural aristotélico, a qual, em brevíssimos - e largamente temerários traços - pode ser sintetizada nos seguintes termos: se o indivíduo, no Estado da Natureza, é livre, nada o pode obrigar, salvo o seu consentimento. Por conseqüência a origem única das regras jurídicas, por definição obrigatóPor consequencia a origem ucordo de vontades, vale dizer, o consenso. ${ }^{10}$

É sabido que as razões ideológicas dessa concepção originada na Ordem dos Franciscanos se assentam numa disputa política entre a Ordem e o Papado culas nência da vontade, empenhados que estão em demonstrar que a soberania do nência da vontade, empenhados que estão em demonstrar que a sober un "direi, o direito de propriedade privada e correlatos não são impostos por um "direito natural" preexistente à sociedade, aistórico e atemporal, na medida em que constituem "criações arbitrárias e históricas" na origem das quais está o indivíduo, se associando aos outros indivíduos e criando as instituições jurídicas, por sua própria vontade, a qual não é, como queria Tomás de Aquino, "serva do intelecto", mas é autônoma e criadora."

4. Acresce que o direito canônico, por sua vez, permeando no direito ro4. Acresce que o direito canônico, por sua vez, perma a idéia de que a quebra da palavra dada quando estabelecido um acordo constituía um pecado e, por isso mesmo, a quebra da palavra alheia teria força liberatória da observância da própria promessa: frangenti fides non est fides servanta foi um princípio canônico de conseqüências profundas no Direito laico. ${ }^{12}$

Por essas vertentes, o antigo adágio romano restou invertido. Se o mero consenso obrigava ${ }^{13}$ e o seu descumprimento constituía um pecado, ex nudo pacto oritur actio. ${ }^{14} \mathrm{E}$ se os instrumentos pelos quais o consenso se expressa

9 Ver Michel Villey, op. cit.

10 Idem, p. 274.

11 Idem, ibidem

12 O princípio foi estatuído numa carta de Inocêncio III aos arcebispos da França e aos católicos franceses, para liberá-los do respeito à pessoa e aos bens do Conde de Toulose, em razão de homicídio de um representate papal praticado por vassalo do Conde. Foi, o princípio, transformado em regula no Liber Sextus de Bonifácio VII dai passando à Compillatio I de fundava o direito do marido de quebrar o juramento de fidelidade matrimonial se a esposa fornicasse A mesma idéia informará o direito de resolução em matéria contratual. Ver Ugo fornicasse. A 1989, v. 40, p. $1297-8$.

1989, v. 40, p. 1297-8. 13 O brocardo solus consensus
posteriormente, no direito civil.

Organon $19 / 1992$ 
sĩo as palavras, justamente por isso elas não podem ser quebradas. "On lie les boefs par les cornes et les hommes par les paroles; autant vaut une simple promesse ou convenance que les stipulations du droit romain", afirmava, com perspicácia, a tradição popular expressa em alguns coutumes franceses medievais. $^{15}$

A confluência destes raciocínios, que interessam profundamente - por suas consequiências - a Teoria Geral do Direito, podem ser rastreadas nas obras de Hugo Grotius, ${ }^{16}$ Thomasius, Pufendorf, Hobbes, Locke, Rousseau e, para o que aqui mais de perto nos concerne, num específico conceito de contrato que há duzentos anos vem permeando as atividades de juristas, legisladores, advogados, intérpretes do Direito.

O conceito aí desenhado se afasta, no entanto, daquele passível de ser deduzido dos textos normativos atuais, como é exemplo o recente Código de Defesa do Consumidor. ${ }^{17}$ Até que ponto a idéia de contrato se encontra abalada, destruída ou transformada atualmente? $O$ que se pretendeu tutelar, no antigo e no novo sistema? O que há por detrás do véu, por vezes espesso e obscuro, da lei?

\section{II - A FORÇA DA VONTADE}

5. Embora advenha do Direito Romano a estrutura mais longíqua do nosso sistema jurídico, é na filosofia moderna que encontraremos o segredo de sua forma. Esta, todavia, como já afirmava Michel Villey, ${ }^{18}$ levou cinco séculos para incubar a civilística de modo que a idéia da vontade como expressão suprema e inderrogável da liberdade individual alcança o Código de Napoleão na forma de sua síntese: se a lei e os contratos são as fontes das obrigações, "os efeitos jurídicos que não fluíssem da vontade seriam derivados da norma", elevando-se a vontade, "com esse procedimento, à categoria de lei" ${ }^{19}$ Daí o contrato ser considerado fonte primordial das obrigações juridicamente vinculantes como e enquanto manifestação da vontade individual.

O axioma posto no artigo 1134 do Código Civil Francês - "les conventions légalement formées tiennent lieu de lois à ceux qui les ont faites" - foi, como bem lembrou André-Jean Arnaud, bem mais do que um axioma: ele foi a expressão de todo um sistema filosófico adaptado ao Direito. ${ }^{20}$ Durante al-

\section{Cf. Jean-Louis Gazzaniga, op. cit. p. 39.}

15 Idem, ibidem.

$16 \mathrm{Em}$ sua Introduction au droit hollandais Grotius define o contrato com um ato voluntário e considera a liberdade individual a única criadora do vínculo contratual. Afirma ainda que "fides é a forma de pensar na qual são possiveis os contratos". (Ver G. Augé, Le contrat et l"evolution

17 Lei Federal $n^{2} 8.078 / 90$.

18 La pensée moderne et le système juridique actuel, in Leçons de philosophe du droit, cit. p. 51 . 19 Conforme Clóvis do Couto e Silva, A obrigação como processo, São Paulo, José Bushatsky Editor, 1976, p. 82

20 Op. eit. p. 197. gum tempo tal noção serviu, sozinha, para designar todo e qualquer tipo do vinculação obrigacional que resultasse da bilateralização da vontado individual. Um século mais tarde uma outra noção, mais sofisticada e abrangente, alcança, por obra da Pandectística alemã, o segundo grande paradigma do fenômeno chamado Codificação: no Código Civil Alemão, vigente em 1900, so encontra a noção de negócio jurídico, noção eminentemente "técnica" 21 que serviu para respaldar - vigorante, já, o capitalismo industrial - uma liberdade contratual que se queria sem limites, vale dizer, sem entraves à circulação do crescente tráfico econômico. ${ }^{22}$

Portanto, aí se traça mais uma associação imprescindível, ao meu ver, para que se compreenda o conceito tradicional de contrato: em razão da força atribuída a vontade, contrato e codificação são, em medida histórica, também conceitos correlatos.

6. O fenômeno da Codificação que marca o século XIX, em coincidência não casual com a consolidação dos grandes Estados contemporâneos, conduziu a Europa Continental à criação de corpos sistematizados ${ }^{23}$ de leis destinados a regular em abstrato situações análogas, se tratando, portanto, de corpos legislativos suscetíveis de leitura uniforme, "certa" e "segura" por juristas profissionais - professores, juízes, advogados, doutrinadores. ${ }^{24}$

$\mathrm{Na}$ base dos Códigos encontram-se "les trois piliers du Droit". de que tratou Carbonnier ${ }^{25}$ - a propriedade, a família e o contrato. $O$ propósito foi o de, tornando a lei clara, precisa, acessível ao modelo de cidadão que emerge com a Revolução de 1789 , sistematizar em um corpus unificado todo o ordenamento jurídico. O que ali não estivesse contido seria o "não Direito", o vazio jurídico. A idéia de Código corresponde, portanto, a de um sistema fechado. ${ }^{26}$

21 O termo indica a pretensão de "neutralidade científica" que caracterizou a Pandectística alemã, uma espécie de formalismo científico desenvolvido para a construção de conceitos "puramente" jurídicos.

22 Nesse sentido Hans Hattenauer, Los fundamentos historico-ideologicos del derecho alemán tradução de Miguel Izquierdo Macias Picaves, Madri, Editorial Revista de Derecho Privado, 1981 , p. 96 e ss., e Franz Wiacker, Diritto privato e società industriale, tradução de Gianfranco Liberati, Edizioni Scientifiche Italiane, p. 76 e ss. e Natalino Irti, L'età della decodificazione, Milão, Giuffrè Editore, 1989, p. 3.

23 A palavra denota, neste contexto, o sentido de ordem e unidade. Unidade interna, a qual vinha sendo perseguida desde muitos anos mas se vê contemplada apenas com a eclosão da Revolução de 1789 que acaba com o particularismo jurídico.

24 Ver, entre outros, Nicoló Lipari. Derecho privado - un ensayo para la enseñanza, Bolonha 1980, p. 37 e ss. e Giovani Tarello, Le ideologie della codificazione nel secolo XVIII, parte I, Gênova, 1971 .

25 Em Flexible droit, Paris, 1983.

26 Ver, entre outros, Natalino Irti, cit. e Claus Wilhelm Canaris, Pensamento sistemático e conceito de sistema na ciência do direito, tradução de A. M. Menezes Cordeiro, Lisboa, edição Fundação Calouste Gulbenkian, 1989. Se compreende, assim, por um lado, a célebre assertiva de Voltaire: "Que la loi soit claire, uniforme et précise; l'interpreter, c'est presque toujours la corrompre", na base da qual estava o dogma da separação das funções estatais, pedra de toque da Revolução e garantia "natural" do cidadão, que acabou conduzindo a um tipo de hermenêutica jurídica fundamentalmente exegética. Por outro se compreende as razões de determinada

Organon $19 / 1992$ 
Tributário do conceito de igualdade vigente em sua época, ${ }^{27}$ o Código dos franceses visualiza o contrato como metáfora da garantia conferida aos indivíduos em sua nova relação com o Estado, a volonté générale aparecendo ai como fonte e elemento das relações jurídicas de direito público e privado, e, mais ainda, como a verdadeira força constitutiva das relações essenciais travadas nesses espaços. ${ }^{28}$

Por isso a obra revolucionária.

"Sem dúvida", diz Alain Finkielkraut, "é ao grito de "Vive la nation!' que os revolucionários destruíram o Ancien Régime, mas o que caracterizava esse novo sujeito coletivo não era a originalidade de sua alma, era a igualdade reinante entre os seus membros (...). É, pois, em oposição, ao mesmo tempo, aos privilégios nobiliários e ao absolutismo real que o conceito de nação irrompe na história. A hierarquia social era fundada no nascimento e a monarquia no direito divino. A esta representação da sociedade e a esta concepção do poder, a Revolução francesa substitui a imagem de uma associação voluntária e livre. ${ }^{29}$

E por isso, também se ampliará tanto a categoria do contrato, expressão política, antes do que jurídica, da liberdade individual recém conquistada, categoria que comportará em seu âmbito de abrangência praticamente tudo: do

concepção do princípio da igualdade: este será perspectivado do ponto de vista formal porque concepça dõ é a iqualdade substancial, mas o particularismo jurídico, isto é, a existência de o seu oposto não é a igualdade substancial, mas o particularismo juridico, Isto e, a existência de várias ordens, estatutos, costumes ou direitos, aplicáveis em razão do status pessoal. A igualdade é, pois, perante a lei, que será comum a todos, não importando o estado pessoal. A primeir Constituição revolucionária, na França. por isso mesmo, determinava a elaboração de um código de leis "communes a touts les français".

27 Ver nota supra.

28 a "grandes dicotomias" Bobbio refere, como a primeira "dicotomia reflexa" 28 Ao tratar das "grandes dicotonias" Bobbio daquela travada entre o público sabe essa polarização vem desde a Antiguidade clássica, revelando, contudo, "toda a sua força explicativa na doutrina moderna do direito natural, pela qual o contrato é a forma típica com que os indivíduos singulares regulam as suas relações no estado da natureza, isto é, no estado em que ainda não existe um poder público, enquanto a lei, definida habitualmente como a expressão mais ainda não existe um poder (voluntas superioris) é a forma com a qual são reguladas as relações dos át sútitos cosial. Por isso mesmo, a critica da doutrin cria il do direito natural atacara, basicamente, a ifera que ful Porial, afirmando Hegel que duas razões afastam tal fundamento, a primeira delas consistindo na diversa natureza do vínculo que une Estado e cidadãos, o qual é permanente e irrevogavel, ao contrário do vínculo contratual, transitório e revogável, e a segunda, pelo fato de o Estado poder pretender de seus cidadãos o sacrifício do bem maior, a vida, que é um bem contratualmente indisponivel. (Ver, do autor, Estado, governo, sociedade: para uma teoria geral da política, tradução de Marco Aurélio Nogueira, Rio de Janeiro, Paz e Terra, 1987, p. 17-9).

$29 \mathrm{Em}$ La défaite de la pensée, Paris, Editions Gallimard, 1987, grifei. No original: "Sans doute

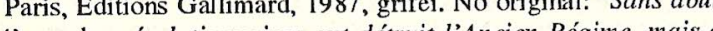
est-ce au cri de 'Vive la nation!' que les revolutionnaires ont deirnir l'Ancien Regime, mais ce qui caractérisait ce nouveau sujet collectif, ce n'était pas l'originalité de son âme, c'étai l'égalité regnant entre ses membres. (...). C'est donc en s'opposant tout à la fois aux privilèges nobiliaires et a l'absolutisme royal, que le concept de nation a fait irruption dans l'histoire. La hierarchie sociale était fondée sur la naissance, et la monarchie sur le droit divin. A cette représentation de la societé et à cette conception du pouvoir, la Révolution française a substituce l'image d'une association volontaire et libre (p. 23 e 25). casamento à compra de um livro ou de um imóvel, da aquisição de ações ou da constituição de uma sociedade comercial à própria concepção da sociedado civil. A antiga assertiva de Pufendorf no sentido de que o contrato "peut tout" é estendida e se dirá, inspirando-se naquela idéia, que o contrato "est tout".

7. A concep̧̧ão do contrato como manifestação da vontade humana em si e por si mesma considerada terá imensas consequiências na ordem prática quo ao Direito - experiência humana concreta, cotidiana - cabe prever e regulamentar. Entre essas está a proteção que foi conferida quase que exclusivamente a um dos pólos da relação jurídica contratual, o credor, manifestante da vontade que é sacralizada. Deflui dessa concepção toda a teoria das nulidades dos atos jurídicos, pela qual são definidos certos "vícios da vontade" os quais, ferindo o ato em sua gênese, acabam por conduzir à expulsão daquele ato, viciado, do mundo jurídico. A vontade viciada é considerada uma "vontade não livre" e, por essa razão, não tem força para produzir efeitos. O que significa, em outras palavras, que a falta da liberdade na emissão da vontade é considerada um defeito que contamina todo o ato.

Detenho-me neste ponto - o contrato como expressão jurídica e política do indivíduo livre, tal como forjado em pleno auge do Iluminismo. Aí, contrato e contratualismo se encontram e duas vertentes iniciam fecunda trajetória na valorização, a um só tempo jurídica e política, da vontade humana: no campo do Direito Público o Estado, concebido como produto da vontade humana, conduz ao conceito de nação como "un corps d'associés vivant sous une loi commune", conforme escreveu Sieyès. ${ }^{31}$

Com base nessa premissa quebrou-se o Absolutismo, daí decorrendo os fundamentos da soberania popular, das liberdades públicas e a noção da le como expressão da vontade geral - caminho pelo qual chegaremos à democracia moderna. Com efeito, os revolucionários franceses "acreditaram reiterar o pacto original que está na origem da sociedade ${ }^{\prime \prime 32}$ e por isso mesmo enfrentaram os argumentos dos conservadores para os quais tal idéia não passava de uma quimera capaz de ser colocada num posto de honra "parmi les actes de folie les plus mémorables". ${ }^{33}$

É preciso, no entanto, não esquecer que outra vertente, centrada na mesma premissa de base, deslocará o eixo para a valorização da vontade do Esta$d o$ : a lei será então concebida como expressão da vontade estatal, plantadas, assim, as sementes do totalitarismo e a conseqüente relevância atribuída às "razões de Estado", em detrimento das razões do indivíduo enquanto membro e fonte de legitimidade do próprio Estado. ${ }^{34}$

30 Assim Jean-Louis Gazzaniga, op. cit. p. 39.

31 Qu'est-ce que le tiers-état, P. U. F., Paris, 1982, p. 31

32 Alain Finkielkraut, op. cit. p. 25.

33 A expressão é de Joseph de Maistre, Oeuvres complètes, v. 1, Lyon, 1884, p. 230 apud Finkielkraut, op. cit. p. 25. 
8. No campo do Direito Privado, por sua vez, idêntico substrato teórico leva ao delineamento do contrato como fonte primordial de direitos e obrigações. A construção que é levada a efeito na Alemanha acerca do conceito de negócio jurídico acompanha, por sua vez, pari passu, o apogeu da burguesia como classe em ascensão, a grande autora do modelo jurídico de sociedade legado ao século XX.

Me parece que tais concepções podem ser rastreadas também no mais célebre dos Fausto, o de Goethe. O primeiro Fausto foi escrito nos fins do século XVIII - apogeu do Iluminismo que tão profunda repercussão terá nos redatores do Code Napoléon - refletindo uma figura que é "a representação dramática do homem da segunda metade do século XVIII", enquanto que o Fausto da versão definitiva, nas primeiras décadas dos Oitocentos - contemporâneo, pois, ao Code -, "representará o modelo absoluto do homem do período racionalista, encarnando o otimismo do progresso" $\mathrm{e}$ "anunciando a obra de civilização do progresso, também econômico, da segunda metade do século $\mathrm{XIX}^{\prime \prime} 35$

É preciso, pois, compreender o significado dessa particular noção de progresso - o seu significado e, bem assim, as suas conseqüências no mundo do direito.

\section{III - A OBJETIVAÇÃO DA VONTADE E A MASSIFICAÇÃO SOCIAL}

9. O progresso econômico no qual o cenário de Fausto se desenrola, o otimismo que o personagem encarna, nós o sabemos, tem as suas bases nas novas formas de estruturação econômica da sociedade e nas descobertas científicas - em especial o transporte ferroviário - que teriam justamente no contrato a sua mais útil ferramenta. ${ }^{36}$ Ao Direito cabia dar os instrumentos que pudessem oferecer as garantias à implementação dos valores dominantes, ${ }^{37}$ aos fins propostos por tais valores, aos objetivos do indivíduo pós-revolucionário.

E é exatamente o prosseguimento, em ritmo febril, dessa particular concepção de progresso que conduzirá, já no final do século XIX, à primeira

34 Nesse sentido M. Villey, Essor et decadence du voluntariste juridique, cit. 35 As citações são de Ludwig Scheild, O Fausto em tempos de crise, in Fausto na literatura portuguesa e alemã, Coimbra, Edição Instituto Nacional de Investigação Científica, 1987, p. 135-54.

36 Como bem assinala Hobsbawn, embora a burguesia não pudesse ainda ser tida como a classe dirigente, é incontestável o fato de que exercia a hegemonia. Não havendo alternativa para o capitalismo como método de desenvolvimento econômico, naquele período, o seu programa cconômico e institucional tornou-se o dominante. (Ver $A$ era do capital, tradução de Luciano Costa Nes Rio de Jano

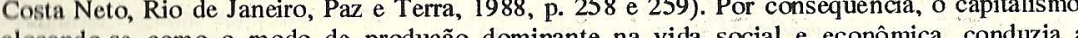
alocando-se burguesia ascendente a requerer os instrumentos jurídicos e políticos que sustentassem a livre circulação de bens.

37 Nesse sentido Natalino Irti, op. cit. p. 4. grande transmutação do conceito moderno de contrato. O burguês, já năo maî̉ o cidadão revolucionário, almeja e constrói o que Stefan Zweig magnilicamente denominou de Die Welt von Gestern, o mundo da segurança, fórmula a qual, no dizer de Natalino Irti, que a repete em ensaio célebre, "coglie il signlficato dell' epoca con la lucida transparenza delle intuizioni artistiche" ${ }^{\prime \prime}$

Esse mundo, onde a vida é perspectivada como "escolha de fins" e onde para escolher os fins o indivíduo deve exercitar o poder e assumir a responsabilidade pela escolha de iniciativas que não defere a mais ninguém ${ }^{39}$ é o mundo da crença no capitalismo, na empresa privada competitiva, na ciência, na tecnologia, no governo representativo, na separação entre o Estado e a Sociedade Civil, no afastamento entre o Direito e a Moral. Desenha-se, o seu espaço, num quadro de industrialização e urbanização crescentes que determinarão o incremento, a níveis até então jamais vistos, do tráfico social, o qual requererá, por sua vez, a construção de formas que assegurem, justamente, a segurança deste tráfico, a sua "normalidade".

10. Um dos objetivos da substituição da Teoria da Vontade como fundamento do vínculo contratual é o de diminuir as possibilidades de invalidação dos negócios por erro, um dos "vícios da vontade". Se busca, então, assegurar proteção também ao outro pólo da relação jurídica contratual - o devedor, destinatário da "manifestação de vontade". Por conseqüiência, é formulada, em substituição à "Teoria da Vontade", a "Teoria da Declaração". Nesta, não importa tanto a manifestação de uma vontade humana subjetivada, mas a sua declaração, isto é, o aspecto externo, "social", da vontade humana. ${ }^{40}$

Por essa via resta inaugurada a trajetória da objetivação do elemento volitivo. Neste século, os contratos, progressivamente, serão vistos não mais como a expressão da liberdade intrínseca do ser humano como "meios de auto-regulamentação dos interesses privados", ${ }^{41}$ na contraposição com aqueles que são hetero-regulamentados pela imposição estatal. Se passa, então, a caracterizá-los como "atos sociais, pelos quais os particulares, nos limites estabelecidos pela ordem jurídica, realizam os seus próprios interesses, disciplinando-os para o futuro, inserindo-os na ordem social ${ }^{42}$ e, por seu intermédio, atuando nessa mesma ordem.

Mais do que tudo, o conceito de contrato perde a univocidade. Em contraste ao "mundo da segurança" retratado por Zweig, vive-se a época do fim

38 É com a fórmula de Stephan Zweig que Irti inicia o ensaio aqui já citado, L'età della decodificazione.

39 Natalino Irti, op. cit. p. 4.

40 Ver Clóvis do Couto e Silva. Para uma história dos conceitos no direito civil e no direito processual civil: a atualidade do pensamento de Otto Karlowa e de Oskar Büllow, in Revista do Processo v. 37, São Paulo, Editora Revista dos Tribunais, 1987.

41 Segundo a célebre definição de Emilio Betti.

42 Conforme Orlando Gomes, Transformações gerais do Direito das obrigações, São Paulo, Editora Revista dos Tribunais, 1980, pp. 47 e ss.

Organon 19/1992 
das certezas. Afigura-se um tempo no qual o contrato não mais repousa sobre um fundamento sem falhas. ${ }^{43}$ Se discute, de um lado, o que os doutrinadores da common law chamam de freedom of contract, de outro o contrato é apenas o instrumento dos planos econômicos governamentais. Outra teoria pretende explicá-los através da análise econômica, como uma relação de custo-benefício. ${ }^{44}$ De toda a forma, caminha-se na direção da objetivação do elemento volitivo e se pode afirmar que, nesta perspectiva, de pouco importa o modo como, nos contratos, se exterioriza a vontade humana: ela pode existir, mas o essencial será o relevo que lhe será conferido pelo ordenamento jurídico.

11. Essa tendência à objetivação do conceito de contrato e a conseqüente "descoberta" dogmática da existência de deveres de conduta que decorrem de vínculo contratual independentemente da vontade dos sujeitos que o estabele$\mathrm{cem}^{45}$ - conseqüência, por sua vez, da reaproximação entre a Moral e o Direito, afastados no Liberalismo - se mostra, com efeito, a única via hábil ao enfrentamento e regulação das complexas relações jurídicas de uma sociedade marcada pela massificação social, pela estandardização dos comportamentos, pela explosão demográfica e pelo fenômeno que se convencionou chamar de "relações jurídicas de consumo".

Me afasto aqui, portanto, da concepção de pacto para entrar na concepção estrita e atual de contrato de massa, aquele que todo o dia estabelecemos ao comprar um sapato, ao adquirir uma passagem aérea, ao parar, com um aceno, o táxi que nos transporta para casa, ao requerer os serviços os mais corriqueiros - de uma lavanderia ou de um supermercado, por exemplo ${ }^{46}$ - porquanto hoje a idéia de contrato apenas residualmente está referenciada ao contrato individual. Quantitativamente, ao menos, essa idéia está polarizada pelo que ocorre, cotidianamente, na sociedade de massas.

12. Inúmeros estudos têm versado, já há longos anos, a massificação social e os seus reflexos no campo do Direito: a explosão demográfica, a expansão da classe média e o seu acesso crescente aos bens de consumo - ao menos nos países desenvolvidos - questões ligadas às novas formas de vida urbana, ao

43 Assim Denis Tallon, op. cit, p. 82: "le temps n'est plus òu le contrat était présenté comme reposant sur un fundament sans faille".

44 Assim os trabalhos dos norte-americanos Richard Posner e Roland Coase. Para uma análise ver Interpretazione giuridica e analise economica, de Guido Alpa et alii, Milão, Giuffrè Editore, 1982.

45 Para esse exame, ver Clóvis do Couto e Silva, A obrigação como processo, cit.

46 Alguns doutrinadores têm afastado certos comportamentos típicos das relações de massa do âmbito do direito contratual, afirmando constituírem "relações contratuais de fato", "condutas socialmente típicas" ou "atos existenciais", reconduzíveis à categoria dos atos-fato e não do negócios jurídicos. Ver, no Brasil, a análise procedida por Clóvis do Couto e Silva in O principio da boa fé no direito civil brasileiro e português, ensaio integrante de Estudos de direito civil brasileiro e portugues. São Paulo, Editora Revista dos Tribunais, 1987. No direito alemão ver Larenz, Derecho de obligaciones, Tomo I, p.58-64, tradução de Jaime Santos Briz, Madri, Editorial Revista de Derecho Privado, 1958. atual estágio do capitalismo, às linhas de força da economia mundial projetam eficácia em todas as províncias da ciência jurídica. Nenhum de seus campos, contudo, parece ter sido mais afetado pela estandardização social do que o di reito das obrigações, e em especial o direito dos contratos. Ai, hoje, se verificam inúmeras formas de vinculação negocial, onde sequer se cogita do papel da vontade, a reclamar espaço e qualificação jurídica. ${ }^{47}$ fenômeno:

Em percuciente estudo apontou José Luiz Diez-Picazo justamente esse

"não basta o fenômeno externo da aglomeração ou das multidões para que se possa falar de massas, ou de sociedade de massas. De algum modo, o fato característico, ainda que constitua uma redundância, é que a sociedade não é de pessoas, mas de massas. As massas se pensam como conjuntos humanos nos quais o homem se integra como um ser anônimo e despersonalizado". 48

Evidentemente não se pode enquadrar esses "conjuntos humanos", uniformes e padronizados em seus estilos de vida, em seu comportamento social, mesmo em seus modos de raciocínio, nas formas de suas vestimentas e nas suas necessidades, criadas ou dirigidas pelo mercado de consumo, na mesma moldura recortada por séculos ao individuo, o homem isolado em sua singularidade, sobre o qual se assentou, como base ou justificativa, o padrão da igualdade e da liberdade formais, que estão no substrato político, filosófico e jurídico do dogma da livre e autônoma manifestação contratual. O tema da autonomia da vontade sofre, em conseqüência, um giro radical, que se refletirá na mudança de perspectiva concernente ao tratamento conferido ao contratante fraco, ${ }^{49}$ do qual não cogitaram os códigos civis.

47 Basta pensar nos contratos de adesão, sejam aqueles correntemente firmados nas relações de consumo, em especial, mas não excludentemente, aqueles concluídos com empresas em regime de monopólio, como é o caso dos contratos de fornecimentos de serviços essenciais à vida comunitária, como a água e a energia elétrica. Bem assim os contratos cogentes, como os derivados de situação emergencial de conjuntura, como a venda forçada de bens de consumo. Ha ainda o vasto campo dos contratos normativos, que se caracterizam pela definição imperativa de uma dipe uma disciplina canerada sob seu âmbito e ainda as formulas tipifcadas de contato e acodos que se situam no plano pré-negocial que, por vezes, adquirem eficácia vinculativa, como os pourparlers, as intent letters, os gentlemen's agreement $\mathrm{e}$ outras formas de uso corrente no comércio internacional. (Ver Mario Julio de Almeida Costa, Direito das obrigações Coimbra, Almendina, 1991, p. 201 e ss.) 48 In Derecho y masificación social. Madri, Editorial Civitas, 1987, p. 23 e ss. (traduzi).

$49 \mathrm{O}$ conceito de "contratante fraco" não se reduz à hipossuficiência econômica. Embora a 9 concito de "cons abranja, em certos casos, diz respeito, nas relaçoes de consumo, à parte tecnicamente vulneravel. A "fraqueza" ou vulnerabilidade decorre de um menor poder de um dos contratantes (o consumidor) em face das informações e especificações técnicas sobre as qualidades, especificações, vícios e riscos atinentes ao produto ou serviço objeto do contrato. Há situações em que o consumidor, mesmo tendo uma incontestável superioridade econômica sobre o fornecedor de serviços, é "vulnerável" do ponto de vista do domínio técnico sobre aqueles serviços que foram contratados.

Organon 19/1992 
13. Para tal finalidade as construções da civilística e as reflexões da teoria geral convergem à constatação de que o eixo da relação contratual se desloca da tutela da vontade à tutela da confiança (Treu und Glaben) e a proteção da boa fé objetiva. ${ }^{50}$ Com isto se quer significar que, no direito contemporâneo, o direito dos contratos não surge exclusivamente dos princípios da autodeterminação e autovinculação, admitindo-se a existência de vinculação - e, portanto, de responsabilidade patrimonial - derivadas, certas vezes, da legítima confiança despertada na contraparte em razão de determinadas condutas adotadas, tendo sido admitida, igualmente a incidência, nas relações reguladas pelo direito privado, dos princípios de valor deduzidos do ordenamento jurídico, inclusive aqueles ainda pré-positivos e, bem assim, dos princípios constitucionais, com o fim de ser garantido um padrão mínimo de justiça material. $^{51}$

Neste particular a Constituição - "sistema aberto de regras e princípios $^{\prime \prime 52}$ - é perspectivada, hoje, como determinante do conteúdo das leis e as garantias fundamentais que arrola, são vistas, à diferença do que ocorria no passado, como princípios objetivos $e$ ativos. O que equivale a dizer que tais princípios são visualizados também do ponto de vista positivo e não apenas negativo - quando sua função consistia em garantir aos indivíduos uma esfera protegida contra o Estado - de maneira que as leis, e a interpretação que lhes será conferida, estarão adstritas a proteger as liberdades e os direitos assegurados, seja contra a ameaça do Estado, seja contra a ameaça de grupos sociais poderosos, seja como matriz de instrumentos ou intervenções que viabilizem tais garantias. 53

50 Compreende-se por boa fé objetiva o delineamento de um padrão ético, modelo de conduta sompreendese pritic justar a própria conduta ao padrão do homem reto, honesto, atuando como atuaria o homen honesto e leal. Por este arquétipo se desconhece, do ponto de vista jurídico, o aspecto subjetivo, vale dizer, a consciência psicológica de estar agindo conforme ao direito, levando-se em consideração, ao contrário, fatores objetivos, a serem verificados sempre in concreto, tais como as circunstâncias do caso, o status cultural ou econômico dos envolvidos, não se admitindo uma aplicação mecânica do standard, do tipo meramente lógico-subsuntivo. (Ver, entre outros, Clóvis do Couto e Silva, $A$ obrigação como processo e $O$ princípio da boa fé no direito brasileiro e português ambos citados, Ernesto Wayar, Derecho civil: obligaciones Buenos Aires, Edisiones Doruges 1990, Franz Wieacker, El prinetpo general de la buena fe, Badueno de Jase los Mozos, Madri, Editorial Civitas, 1976, A. M. Menezes Cordeiro. Da boa fé no direito civil Coimbra, Almendina, 1984, Domenico Corradini, Il criterio della buona fede e la scienza de diritto privatto, Milão, Giuffrè Editore, 1971 e o meu comentário à jurisprudência do TJRGS, O principio da boa-fé, Revista Ajuris, v. 50, Porto Alegre, 1990

51 Nesse sentido Claus Wilhem Canaris, op. cit., e Joseph Esse, Principio y norma en la elaboración jurisprudencial del derecho, tradução de Eduardo Valenti Fiol, Barcelona, Bosch, 1961. Ainda sobre os princípios, Ronald Dworkin, Los derechos en serio, tradução de Marta Guastavino, Ariel, Barcelona, 1989.

52 A expressão é de J. J. Gomes Canotilho, in Direito constitucional, 5a edição, Coimbra, Almendina, 1991.

53 Nesse sentido ver, entre outros, Dieter Grimm, La constitución como fuente del derecho, in Las fuentes del derecho, Ed. Universitat de Barcelona, 1983, pp. 13 a 26 e Konrad Hesse, A forca normativa da Constituição, tradução de Gilmar Ferreira Mendes, Porto Alegre, Sergio Fabris
No campo das relações contratuais de massa admite-se, assim, a inief: venção legislativa, administrativa e judicial na "declaração de vontude" ex: pressa nos contratos para adequá-los ao já aludido padrão de justiça contratual material. Em particular no que concerne aos contratos de adesão se entende que, embora o direito contratual possua, em regra, natureza dispositiva, estes se configuram por seu caráter cogente, impositivo, de modo que o juiz, ao examiná-los no confronto com os princípios de justiça substancial e boa fé objetiva, pode eliminar as cláusulas atentatórias ao equilibrio contratual, declarando a sua nulidade, ${ }^{54}$ assegurando-se ao consumidor os meios conducentes a buscar a nulidade de qualquer cláusula contratual que "de qualquer forma não assegure o justo equílibrio entre direitos e obrigações das partes".

14. Nesta perspectiva, devidamente discernido o papel da vontade, visualizado o sistema jurídico não mais como um sistema fechado que se auto-referencia de modo absoluto - mas como um sistema relativamente "aberto" às interseções de valores éticos, e de elementos históricos e sociais, tradicionalmente tidos como metajurídicos, ${ }^{56}$ - se legitima a intervenção estatal no vínculo que, por séculos, esteve fundado no espaço sacralizado da vontade individual. A relação entre contrato e comutatividade, de onde provém, inclusive um dos critérios aristotélicos da justiça, poderá, talvez, assim ser retomada. ${ }^{57}$

A excessiva valorização juridica da subjetividade teve por efeito não só afastar as noções de contrato e comutatividade, ou equilibrio entre as prestações, como conduziu, muitas vezes, à anulação do indivíduo que já não pode, como o Fausto de Goethe exclamar - Bin ich Gotr? - pleno de poder e com a alma "luminosa de felicidade", 58 porquanto se transmutou, na sociedade de massas, no seu anônimo, uniforme e despersonalizado integrante. Resta saber se, aí, o conceito de contrato poderá, ou não, continuar a ser caracterizado como pacto.

\section{Editor, 1991.}

54 Assim a disposição do art. 51, IV, da Lei no. 8078 ("Código de Defesa do Consumidor") segundo a qual, são nulas de pleno direito as cláusulas contratuais relativas ao fornecimento de produtos ou serviços que "estabeleçam obrigações consideradas iníquas, abusivas, que coloquem produtos ou serves a (grifei).

55 Redação do parágrafo $4^{\circ}$ do artigo. 51 da Lei n. 8.078, antes referida.

56 Escrevi sobre o tema "As cláusulas gerais como fatores de mobilidade do sistema jurídico", Revista dos Tribunais v. 680, São Paulo, 1991 e Revista de Informação Legislativa v. 112 Brasília, 1991.

57 Uma das vertentes de análise desse ponto reside na chamada "Teoria da base objetiva do 57 ma das vertentes de analise "A teoria da imprevisão e a incidência dos planos governamentais na relação contratual", Revista dos Tribunais, v. 670, p. 41-8, São Paulo, 1991.

governamentais na relação contratual", Revista dos Tribunais, v. 670, p. 41-8, São Paulo, 1991.
58 "Sou eu, então, um deus?", exclama Fausto quando, abrindo o livro mágico de Nostradamus e atravessando o macrocosmo, pode ver, "para além das aparências", o "harmônico operar da Natureza". (Conforme Dizionario delle opere e dei personaggi, Milão, Valentino Bompiano Editore, v. 3, p. 313-36, 1947 